F. med. Genet. (1967). 4, 177.

\title{
A Case of Translocation (C/14) with Mental Retardation in Two Offspring*
}

\author{
D. B. PITT, G. C. WEBB, JACQUELINE WONG, MERRYL K. ROBSON, and \\ JEAN FERGUSON
}

From the Paediatric Unit, Children's Cottages Training Centre, Kew, Victoria; the Department of Genetics, University of Melbourne; and the Research Department, Australian Commonwealth Serum Laboratories, Parkville, Victoria, Australia

A family is presented in which a reciprocal translocation in the mother is associated with the birth of two defective children, one of whom had a chromosomal abnormality. The karyotype of the mother, studied by autoradiography, appears to have a segment of the long arm of a late-labelling $\mathrm{D}$ chromosome reciprocally translocated to a $\mathrm{C}$ chromosome in exchange for a terminal segment of the short arm of the latter chromosome.

The pedigree is shown in Fig. 1. The mother, phenotypically normal, was born in 1934, the father, also phenotypically normal, in 1928; they are unrelated. Other members of generations I and II were said to be normal, except for three second cousins of the mother, said to be 'deaf and dumb', and a first cousin of the father, said to have syndactyly. These members were not available for examination.

The first child (III. 1), born in 1957, died from bronchopneumonia in the following year at the age of 17 months at the Royal Children's Hospital, Melbourne. When previously examined at the age of 15 months, she was only then trying to pull herself into the sitting position, was unable to crawl, and was regarded as being mentally retarded. There were no physical abnormalities recorded either on clinical examination, or at necropsy.

The second child (III. 2), born in 1960, was clinically normal, with a normal karyotype.

The third child (propositus, III. 3 ) was born in 1962 , and resembled clinically his deceased sister (III. 1). The pregnancy, birth, and neonatal periods were apparently normal but, as in III. 1 , his subsequent development was slow. He did not sit up alone until 10 months, first crawled at about

\footnotetext{
Received January 16, 1967.

* Supported in part by a University of Melbourne Research Grant to G.C.W.

12 months, and first walked at 22 months. He was admitted to the Paediatric Unit (Children's Cottages Training Centre) at the age of 3 years.

\section{Material and Methods}

Blood cultures were prepared and harvested according to the method of Moorhead, Nowell, Mellman, Battips, and Hungerford (1960) and were stained with acetoorcein. Skin cultures were prepared and harvested by the method described by Ferguson (1962).

Autoradiographs were prepared by a technique based on that of Frøland (1965), using Ilford K5 dipping emulsion. The cells were prepared by air-drying, treated with $5 \%$ trichloracetic acid to remove acid soluble labelled nucleotides, and stained with carbolfuchsin (Carr and Walker, 1961). Coverslips were temporarily mounted with $50 \%$ glycerol. After photographing suitably labelled metaphases, silver grains were removed, as in Bianchi, Lima-deFaria, and Jaworska (1964) without using trypsin. The cells were restained with $0.25 \%$ toluidine blue and cleared with $95 \%$ ethanol (Prescott, 1964). Where phase optics were used the emulsion was cleared with $0.05 \mathrm{M} \mathrm{NaOH}$ (Caro, 1964).

\section{Clinical Studies}

Physical examination of the propositus (III. 3) was negative, except that the eyes were rather deeply set, and the forehead correspondingly prominent (Fig. 2). There was partial syndactyly of the second and third toes of each foot, a common finding. The height, weight, and head circumference were normal. The urine was negative for phenylketones, and normal for amino acid and indole chromatography. The Guthrie test for phenylketonuria was negative and the skull $x$-ray film was normal. Red cell phosphohexokinase was normal (21.4 units), i.e. not in the range $29.9 \pm 3.0$ units found in trisomic mongolism (Baikie, Loder, de Gruchy, and Pitt, 1965). Psychological examination by the Piaget method showed he had an IQ of 33, which placed him towards the lower end of the moderately 177 

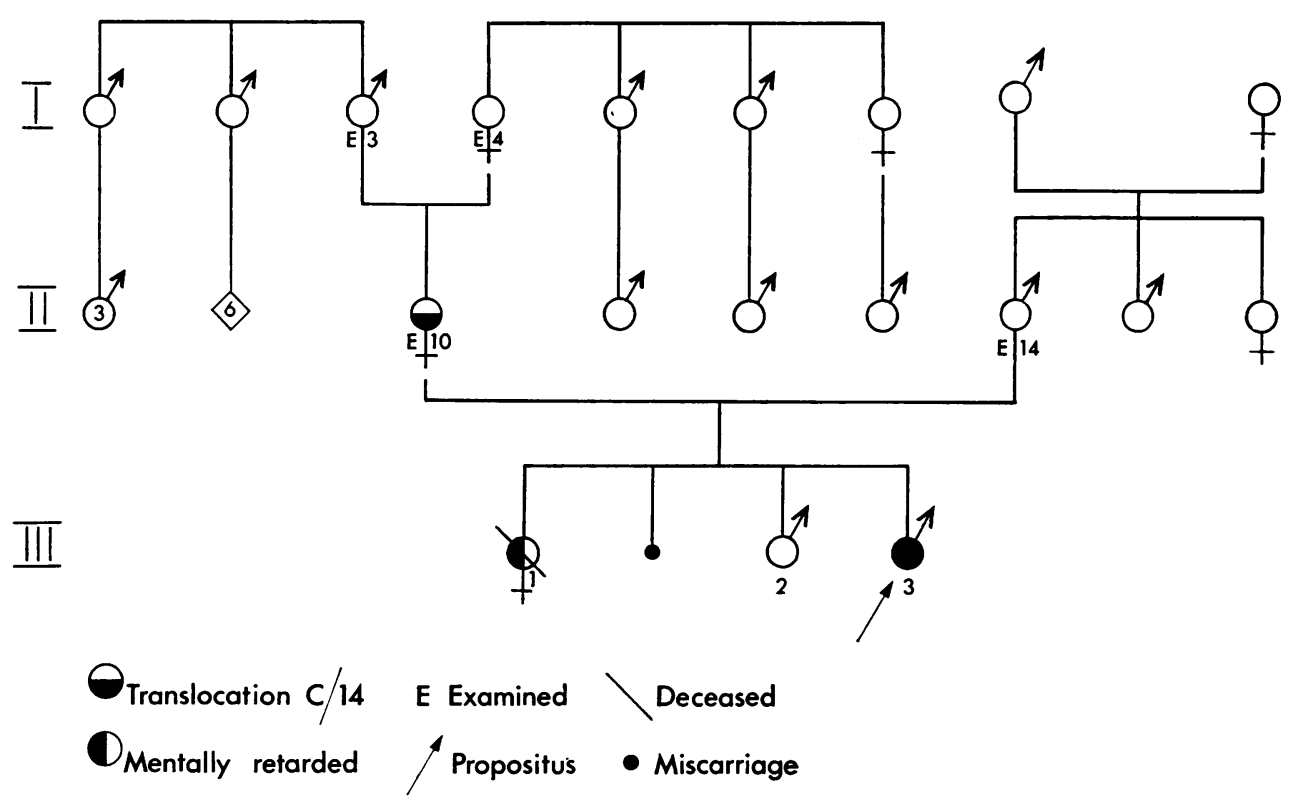

Fig. 1. Pedigree of the family.

\section{Dermatoglyphic Studies}

Quantitative data on total ridge and triradius counts and total palmar main line indices on the propositus and his parents are summarized in Table $I$. The ridge and triradius counts were within the range generally found (Parsons, 1964). The triradius was normally placed in the propositus and his parents (as measured by the total maximal atd angles), which contrasts with the extremely

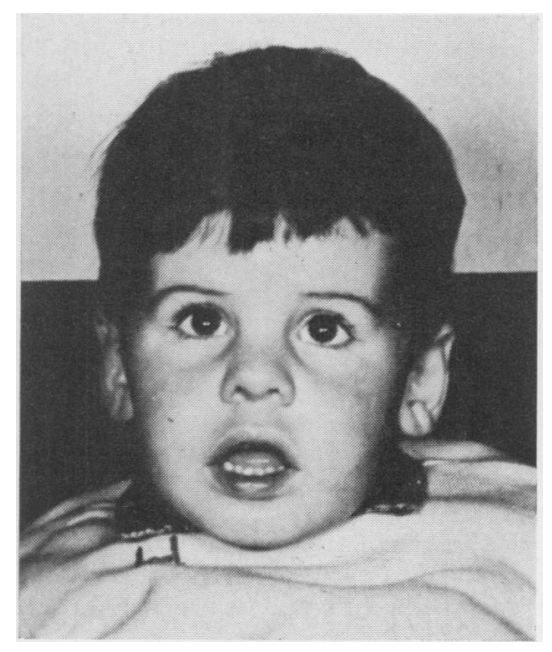

FIg. 2. Propositus (III. 3). distal $t$ triradii generally found in Down's syndrome and $D_{1}$ trisomy.

\section{Cytogenetic Studies}

Both blood and skin cultures of the propositus (III. 3) showed 47 chromosomes with six small acrocentrics, of which one of the five apart from the $Y$ appeared to be slightly larger than the others (Fig. 3). This finding, and the clinical evidence against a diagnosis of Down's syndrome, prompted examination of the parents' chromosomes.

The father (II. 14) and other immediate relatives had normal karyotypes (Table II).

The mother (II. 10) was found to have 46 chromosomes, with an abnormal karyotype in both blood and skin cells. There were only 15 group $\mathrm{C}$ chromosomes (Fig. 4), and only 5 group D chromosomes. A large chromosome morphologically similar to a No. 2 chromosome, and an extra acrocentric chromosome, a little

\section{TABLE I}

Dermatoglyphic Data on Propositus and Parents

\begin{tabular}{l|c|c|c|c}
\hline Subject & $\begin{array}{c}\text { Total Finger } \\
\text { Ridge } \\
\text { Counts }\end{array}$ & $\begin{array}{c}\text { Total Finger } \\
\text { Triradius } \\
\text { Counts }\end{array}$ & $\begin{array}{c}\text { Total } \\
\text { Maximal } \\
\text { atd Angles }\end{array}$ & $\begin{array}{c}\text { Total } \\
\text { Palmar } \\
\text { Main-line } \\
\text { Indices }\end{array}$ \\
\hline II. 10 & 82 & 7 & $83^{\circ}$ & 51 \\
III. 14 & 128 & 15 & $78^{\circ}$ & 52 \\
III. 3 & 123 & 14 & $105^{\circ}$ & 58 \\
\hline
\end{tabular}




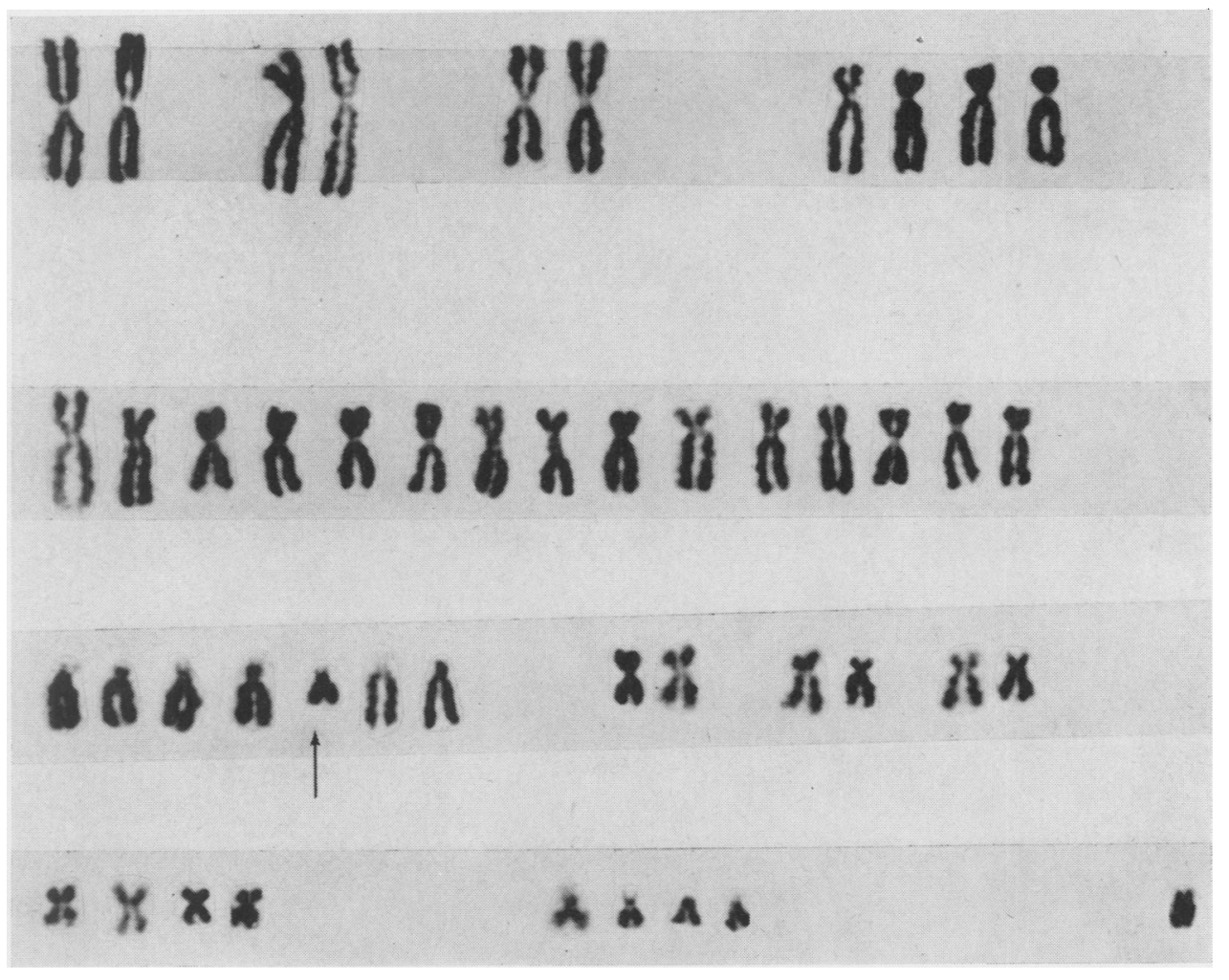

FIG. 3. Karyotype of propositus (III. 3) with proposed translocation chromosome, 14C, arrowed.

larger than those of the $G$ group were found. The abnormal chromosomes appeared to be the result of a reciprocal translocation between the missing $\mathrm{C}$ and $\mathrm{D}$ chromosomes and for this reason are shown in groups $\mathrm{C}$ and $\mathrm{D}$ in Fig. 4. Arm measurements of chromosomes of group $\mathrm{C}$ size suggested that the unpaired chromosome was in the size range 6-8. In 32 cells, an extremely late-replicating chromosome of group $\mathrm{C}$ chromosome size was seen and was presumed to be a normal $X$, so an $\mathrm{X}$ autosome translocation was discounted (Ohno and Cattanach, 1962).

\section{TABLE II}

Results of Chromosome Counts

\begin{tabular}{|c|c|c|c|c|c|c|}
\hline \multirow{2}{*}{ Subject } & \multirow{2}{*}{$\begin{array}{l}\text { Type of } \\
\text { Culture }\end{array}$} & \multicolumn{5}{|c|}{ Number of Chromosomes } \\
\hline & & 45 & 46 & 47 & 48 & Total \\
\hline $\begin{array}{l}\text { I. } 3 \\
\text { I. } 4 \\
\text { II. } 10\end{array}$ & $\begin{array}{l}\text { Blood } \\
\text { Blood } \\
\text { Blood }\end{array}$ & $\begin{array}{r}\overline{2} \\
3\end{array}$ & $\begin{array}{l}34 \\
30 \\
34\end{array}$ & $\begin{array}{l}1 \\
1 \\
3\end{array}$ & $\frac{7}{1}$ & $\begin{array}{l}35 \\
33 \\
41\end{array}$ \\
\hline $\begin{array}{l}\text { II. } 14 \\
\text { III. } 2 \\
\text { III. } 3 \\
\text { (propositus) }\end{array}$ & $\begin{array}{l}\text { Skin } \\
\text { Blood } \\
\text { Blood } \\
\text { Blood } \\
\text { Skin }\end{array}$ & $\begin{array}{l}\bar{z} \\
\frac{1}{1} \\
\end{array}$ & $\begin{array}{r}33 \\
33 \\
30 \\
9 \\
-\end{array}$ & $\bar{z}$ & $\frac{\bar{Z}}{2}$ & $\begin{array}{l}33 \\
33 \\
32 \\
46 \\
36\end{array}$ \\
\hline
\end{tabular}

Two group D chromosomes showed a consistently heavy late label over the central or distal part of the long arm, and were identified as number 13 according to Yunis, Hook, and Mayer (1964). The pair of number 15 chromosomes showed little or no labelling at the end of $S$ phase. A single group D chromosome in the karyotype showed a moderate amount of label distributed over the whole chromosome, particularly the proximal part of the long arm and on the short arms (Fig. 5 and 6). Hence, on the basis of labelling pattern, the most likely $\mathrm{D}$ chromosome involved in the translocation appeared to be No. 14 .

The centromeric portion of the translocated No. 14, subsequently called $14^{\mathrm{C}}$, cannot be accurately distinguished by its labelling from the chromosomes of group G. It was not late labelling, so it was presumed that its long arm has a relatively large terminal segment of early labelling $\mathrm{C}$ chromosome. In cells which showed the above characteristic group D labelling, the large translocation chromosome, $\mathrm{C}^{14}$, showed labelling which often extended to the centromere in the long arm and was dissimilar from the morphologically similar No. 2 chromosomes (see Fig. 5 and 6). The long arm of $\mathrm{C}^{14}$ appeared qualitatively to have a heavier label than the segment of No. 14 homologous to it, but this may be 
due to $\mathrm{C}$ chromosome material present in the arm, or may be an effect of translocation on the segment.

\section{Discussion}

In this family, cytogenetic investigations were undertaken to serve as a basis for genetic counselling. These studies have not only revealed the chromosomal origin of the clinical disorder, but will be useful for giving advice to the normal child. We believe that cytogenetic studies should be done on all familial disorders of obscure type.

The karyotype of the propositus might have been diagnosed as trisomy 21 , save that the child's phenotype was quite different from that found in Down's syndrome, and that the extra chromosome was slightly larger than those of the G group. Meiosis may be expected to occur in the propositus since he is close to the physical norm, and would be the best method of studying the five small acrocentrics (Lindsten, Fraccaro, Klinger, and Zetterquist, 1965). It was felt that autoradiography would not significantly differentiate these five acrocentrics.
The propositus does not appear to be XYY since the extra small acrocentric is morphologically dissimilar from a $\mathrm{Y}$, and his chromosome anomaly appears to be maternally derived.

The sporadic translocation in the mother (II. 10) adds to the large number of reported translocations involving group D chromosomes. In contrast, there are relatively few cases of translocations involving group $\mathrm{C}$ chromosomes. There are two other reports of $\mathrm{D} / \mathrm{C}$ translocations by Stalder, Buhler, Gadola, Widmer, and Freuler (1964) and Weller, Apley, and Raper (1966). Stalder and his co-workers showed that the group $\mathrm{C}$ chromosome involved in the translocation was autosomal by its transmission through males. Approximately half of the long arm of a group D chromosome was transferred to the short arm of a group C chromosome, but was insufficient to make this arm longer than the original long arm, as in the present study. Autoradiography suggested that the $\mathrm{D}$ chromosome involved in this case was a number 13 (G. R. Stalder, 1966, personal communication). Weller 


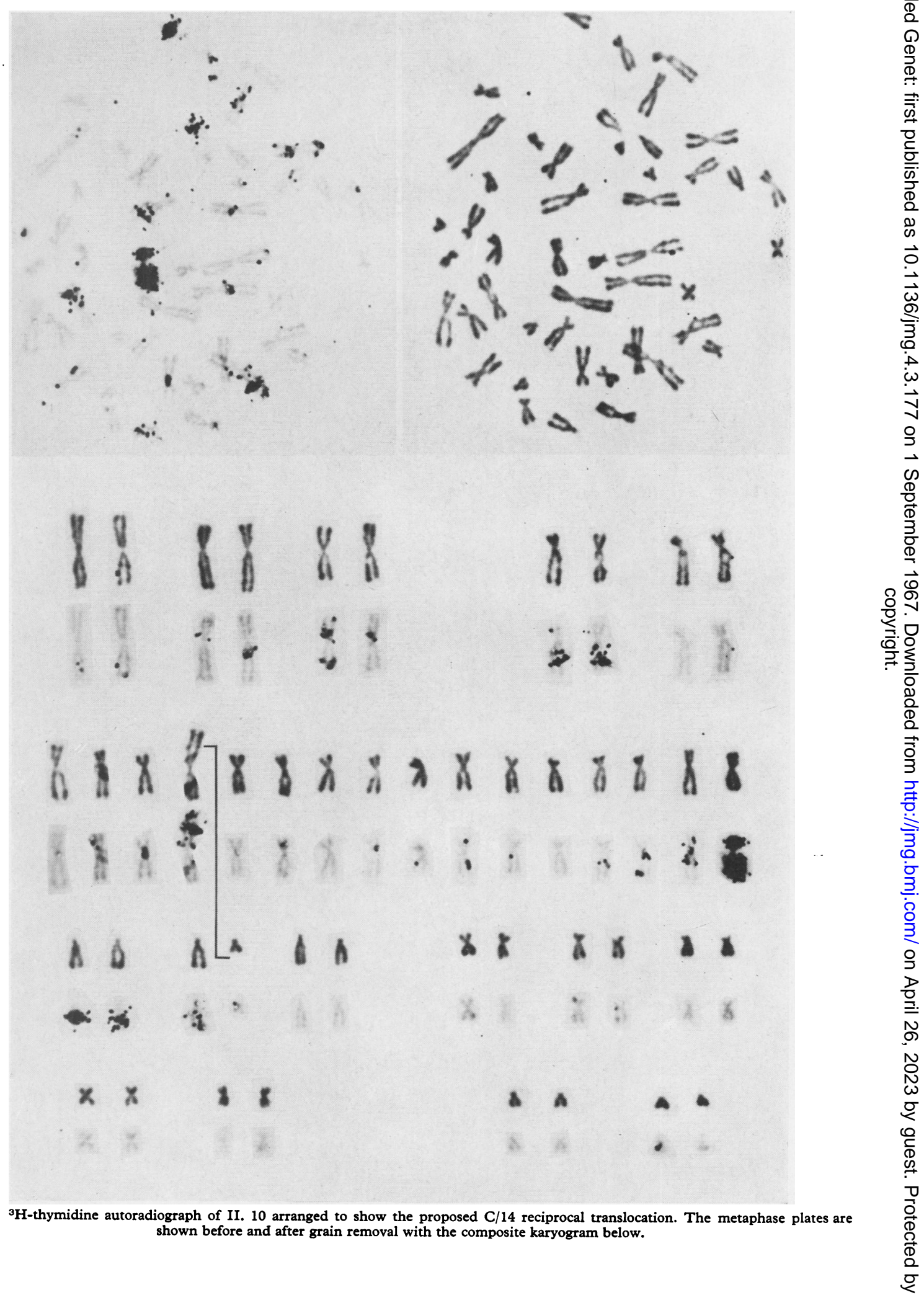




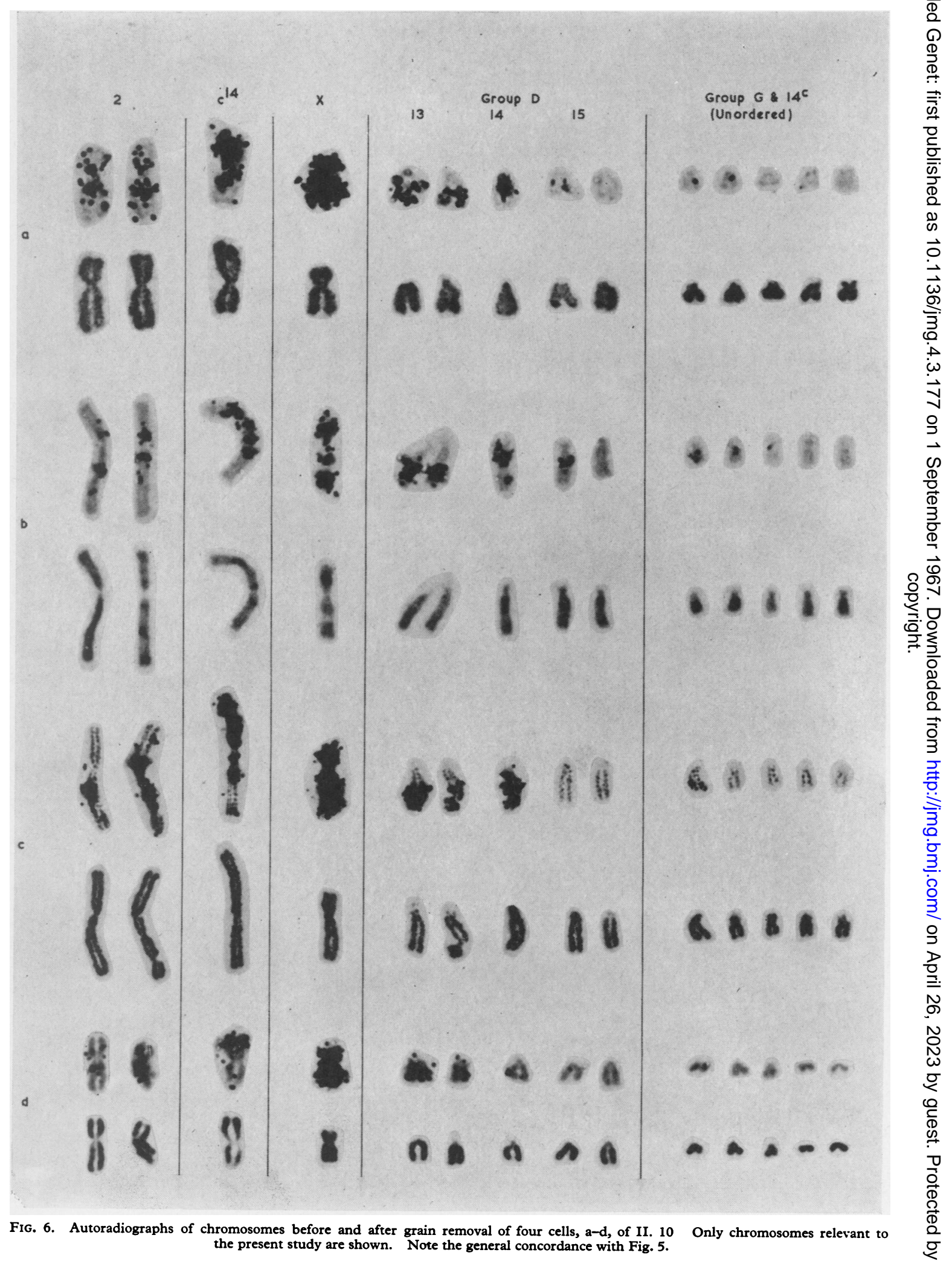



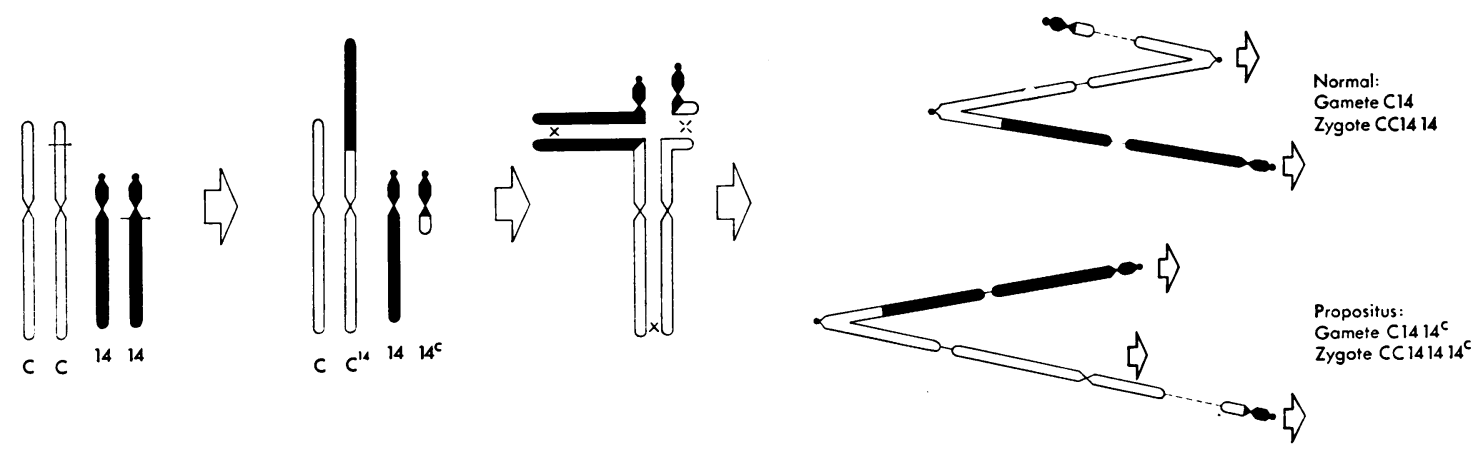

FIG. 7. Diagram showing the suggested meiotic situation in II.10, with the concordant and discordant orientations which could give rise to the normal child and the propositus.

et al. comment on a sporadic reciprocal C/D translocation in which a large $\mathrm{C}$ chromosome has lost approximately one-half of its long arm to the arm of a D chromosome which correspondingly increases in length. The chromosomes were not further identified so that an $\mathrm{X}$ autosome translocation is not entirely excluded.

In the mother (II. 10) a possible meiotic situation is as shown in Fig. 7. It is unlikely that chiasmata will be formed in the proximal region of the short arms of the chromosomes 14 and $14^{\mathrm{C}}$, and break and centromere interference may reduce the frequency of chiasma formation in the distal arm of $14^{\mathrm{C}}$ which is homologous with the short arm of the $\mathrm{C}$ chromosome. If a chiasma occurs between $14^{\mathrm{C}}$ and $\mathrm{C}$, then a quadrivalent would be formed and would display the usual alternate and adjacent segregation. A trivalent and univalent $14^{\mathrm{C}}$ configuration seems more likely, with the univalent segregating to either pole. Either situation is accounted for in Fig. 7, which is restricted to configurations relevant to the present case. Alternate segregation would account for the normal sib of the propositus. The chromosomes of the propositus could be accounted for by a discordant orientation which is symmetrical either as a trivalent and univalent or as a quadrivalent, and would be a likely meiotic configuration (Hamerton, 1966).

\section{Summary}

A case of familial mental retardation is described, which appears to be due to a sporadic translocation in the mother between an autosomal member of the C group of chromosomes and a member of the D group, shown by autoradiographic studies to be probably No. 14. A son, the propositus, has a karyotype resembling trisomy 21 of Down's syndrome, but he was not mongoloid. Possible meiotic situations leading to the formation of the observed karyotypes are discussed.
We are grateful to Professor M. J. D. White for checking the manuscript and to Dr. J. A. Thomson for technical advice. Dr. David Danks and Dr. Bernard Neal (Royal Children's Hospital) have assisted with recording the early history of the propositus, and we are also grateful to Dr. Albert Baikie (University Department of Medicine, St. Vincent's Hospital) and to Miss N. B. Geran (St. Nicholas Hospital) for carrying out special tests. We would also like to thank Mr. $R$. Wilson for photographs, and the Mental Health Authority, Victoria, for facilities to study this case and for permission for its publication.

\section{REFERENCES}

Baikie, A. G., Loder, P. B., de Gruchy, G. C., and Pitt, D. B. (1965). Phosphohexokinase activity of erythrocytes in mongolism. Another possible marker for chromosome 21. Lancet, 1, 412.

Bianchi, N., Lima-deFaria, A., and Jaworska, H. (1964). A technique for removing silver grains and gelatin from tritium autoradiographs of human chromosomes. Hereditas (Lund), 51, 207.

Caro, L. G. (1964). High resolution autoradiography. In Methods in Cell Physiology, ed. D. M. Prescott. Academic Press, New York and London.

Carr, D. H., and Walker, J. E. (1961). Carbol fuchsin as a stain for human chromosomes. Stain Technol., 36, 233.

Ferguson, J. (1962). Chromosome studies of human cells in tissue culture. Med. F. Aust., 1, 40.

Frøland, A. (1965). Photographing recording and dye staining of chromosomes for autoradiography and morphology. Stain Technol., 40, 41.

Hamerton, J. L. (1966). Chromosome segregation in three human interchanges. In Chromosomes Today, ed. C. D. Darlington and K. R. Lewis, Vol. 1, pp. 237-252. Oliver and Boyd, Edinburgh.

Lindsten, J., Fraccaro, M., Klinger, H. P., and Zetterquist, P. (1965). Meiotic and mitotic studies of a familial reciprocal translocation between two autosomes of group 6-12. Cytogenetics, 4, 45.

Moorhead, P. S., Nowell, P. C., Mellman, W. J., Battips, D. M., and Hungerford, D. A. (1960). Chromosome preparations of leukocytes cultured from human peripheral blood. Exp. Cell Res., 20, 613.

Ohno, S., and Cattanach, B. M. (1962). Cytological study of an $\mathrm{X}$-autosome translocation in Mus musculus. Cytogenetics, $1,129$.

Parsons, P. A. (1964). Finger-print pattern variability. Acta genet. (Basel), 14, 201.

Prescott, D. M. (1964). Autoradiography with liquid emulsion. In Methods in Cell Physiology, ed. D. M. Prescott. Academic Press, New York and London.

Stalder, G. R., Buhler, E. M., Gadola, G., Widmer, R., and Freuler, F. (1964). A family with balanced $D^{1} \rightarrow C^{s}$-translocation carriers and unbalanced offspring. Humangenetik., 1, 197.

Weller, S. D. V., Apley, J., and Raper, A. B. (1966). Malformations associated with precocious synthesis of adult hæmoglobin. A new chromosomal anomaly syndrome. Lancet, $1,777$.

Yunis, J. J., Hook, E. B., and Mayer, M. (1964). Deoxyribonucleic-acid replication pattern of trisomy $\mathrm{D}_{1}$. ibid., 2, 935 . 